\title{
La calidad de la comunicación de las Instituciones de Educación Superior del Ecuador
}

\author{
Guillermo Santa-María* \\ Carina Rey-Martin ${ }^{\star \star}$ \\ Lilian Molina-Benavides ${ }^{\star \star \star}$ \\ Arturo Clery ${ }^{\star \star \star}$
}

Artículo recibido:

19 de octubre de 2018

Artículo aceptado:

4 de marzo de 2019

Artículo de revisión

\section{Resumen}

El objetivo del presente trabajo fue determinar el cumplimiento de las atribuciones y funciones de la agencia ecuatoriana que regula la gestión del aseguramiento de la calidad de la educación superior, declaradas en su Plan comunicacional, a través de una investigación exploratoria de las páginas web de todas las universidades reguladas. Para el efecto, se diseñaron estándares a partir del Plan que recogieron la información pertinente a través de un baremo. Los resultados se clasifican con base en seis elementos que el mismo Plan resaltaba, a saber: la gestión de la comunicación,

* Universidad de Guayaquil, Ecuador

guillermo.santamarias@ug.edu.ec carina.rey@ub.edu

** Universidad de Barcelona, España Imolina@upse.edu.ec clery@upse.edu.ec

INVESTIGACIÓN BIBLIOTECOLÓGICA, vol. 33, núm. 81, octubre/diciembre, 2019, México, ISSN: 2448-8321 pp. 13-39 
su difusión y posicionamiento, la imagen de las autoridades, la vinculación con otras universidades, la gestión con instituciones internacionales y el empoderamiento de la misión y visión institucional. Cada uno de estos elementos presenta sus propias características y son analizados en el presente trabajo.

Palabras clave: Comunicación; Calidad; Universidad

The quality of communication in Higher Education Institutions of Ecuador

Guillermo Santa-María, Carina Rey-Martin, Lilian Molina-Benavides and Arturo Clery

\section{ABSTRACT}

The objective of this work was to determine the fulfillment of the attributions and functions of the Ecuadorian agency that regulates the management of quality assurance in higher education, as declared in its Communication Plan, through an exploratory research of the web pages of all regulated Universities. For this purpose, standards were designed from the Plan, which collected the pertinent information through a scale. The results were classified based on 6 elements that the Plan itself highlighted, namely: communication management, its dissemination and positioning, the image of the authorities, links with other Universities, management with international institutions and the empowering of the mission, and an institutional vision. Each of these elements presents its own characteristics and are analyzed in the present work.

Keywords: Communication; Quality; University

\section{INTRODUCCIÓN}

T a calidad, como concepto, se ha desarrollado como respuesta a las deLmandas de los contextos. Hay coincidencia entre los especialistas de que se trata de un concepto complejo, relativo y en consecuencia imposible de conceptualizar de forma unívoca (Villarroel, 2004). 
La aplicación de las teorías de la calidad a la Enseñanza Superior en América Latina, luego de iniciales resistencias, ha sido asumida como necesaria e imprescindible. Desde una visión de las políticas públicas, hoy se admite la existencia de un nuevo pacto entre el Estado y las universidades: la rendición de cuentas por parte de éstas mediante el cumplimiento de determinados estándares de calidad (Toscanini, Aguilar y García, 2016: 163).

Durante la segunda mitad del siglo pasado y las dos primeras décadas del presente, las IES (Instituciones de Educación Superior) en América Latina ajustaron su realidad a la evolución que experimentó este concepto. En la década de 1990 aparece en la agenda de los países latinoamericanos el tema de la calidad como un ingrediente de las reformas a la educación superior (Cielo, Ospina y Vega, 2016).

En Ecuador, la Constitución que entra en vigencia en 1998 determinó, para asegurar los objetivos de la calidad, que las IES estarían obligadas a la rendición social de cuentas, y para ello estableció un sistema autónomo de evaluación y acreditación. En consecuencia, la Ley de Educación Superior que se expide en abril del 2000, en concordancia con el mandato constitucional, contempla un Sistema Nacional de Evaluación y Acreditación, mismo que estaría dirigido por un Consejo Nacional de Evaluación y Acreditación (CONEA) (Cadena, 2014).

Para conseguir la calidad en la educación superior, el CONEA consideraba una red dinámica de interacciones: la calidad del insumo (input), la calidad del proceso (output) y la calidad del resultado (outcome), sosteniendo que en esa red se debían tomar en cuenta elementos como la calidad del impacto educativo en el contexto, la calidad de la oferta, el currículum, la demanda, la calidad del diseño y de la implementación.

En 2008, con la entrada en vigencia, hasta la actualidad, de la Vigésima Constitución de la República, se determinó que el sistema de educación superior se regiría por los principios de autonomía responsable, cogobierno, igualdad de oportunidades, calidad, pertinencia, integralidad, autodeterminación para la producción del pensamiento y conocimiento en el marco del diálogo de saberes, pensamiento universal y producción científica tecnológica global (Molitor, 2009).

Con esta Constitución, la gobernanza del sistema está a cargo de un organismo público de planificación, regulación y coordinación interna del sistema, y de la relación entre sus distintos actores con la Función Ejecutiva; dicho organismo se denomina Consejo de Educación Superior (CES). Un segundo organismo público técnico de acreditación y aseguramiento de la calidad de instituciones, carreras y programas es el Consejo de Evaluación, Acreditación y Aseguramiento de la Calidad de la Educación Superior 
(CEAACES). Ninguno puede conformarse por representantes de las instituciones objeto de la regulación.

En 2010 se aprueba la nueva y vigente Ley Orgánica de Educación Superior (LOES), cuyo objeto es definir sus principios y garantizar el derecho a la educación superior de calidad que propenda a la excelencia (Martínez y Vázquez, 2012: 175). No es el derecho a cualquier educación superior, el texto de forma taxativa coloca la palabra "calidad".

El ingreso a las instituciones públicas de educación superior empezó a regularse a través de un sistema de nivelación y admisión, al que se someten todos los aspirantes; está a cargo de la Secretaría de Educación Superior, Ciencia, Tecnología e Innovación (SENESCYT), en coordinación con el Ministerio de Educación, en lo relativo a su articulación entre el nivel bachiller o su equivalente y la educación superior, procurando sólo el ingreso de estudiantes que cumplan con estándares mínimos.

Con la vigencia de la LOES, el Estado recupera el control del sistema universitario, al tiempo que inicia esfuerzos para que las políticas públicas constituyan instrumentos de comunicación entre el Estado y las universidades (LOES, 2010) y un modo a través del cual los gobernantes buscan cambiar el rumbo, de manera positiva, de las condiciones de pobreza y marginalidad de la población (López, Cifuentes y Palma, 2018).

La LOES vigente desde 2010 hasta agosto de 2018 define, en su artículo 93, al principio de calidad como "la búsqueda constante y sistemática de la excelencia, la pertinencia, producción óptima, transmisión del conocimiento y desarrollo del pensamiento mediante la autocrítica, la crítica externa y el mejoramiento permanente".

El CEAACES, hasta 2018 y además de organizar los procesos de mejoramiento, tuvo en su tarea una clara orientación hacia la depuración. La purga finalizó con la aprobación, por parte de la Asamblea Nacional, de la Ley Orgánica de Extinción de las Universidades y Escuelas Politécnicas, suspendidas por el CEAACES.

El CES, en la motivación de la Resolución que aprobó el Reglamento para la designación y atribuciones de los miembros de la junta del Fideicomiso denominado "Mandato 14 - más calidad", definió ese periodo como el cierre definitivo de una etapa que representó la existencia de instituciones que no cumplían con los parámetros de calidad (Molina, 2015); además, fue considerado una forma de garantizar el derecho a la educación superior de calidad y establecer los mecanismos que aseguren la rendición de cuentas, la distribución y el uso eficiente de los recursos públicos en favor de las instituciones del Sistema de Educación Superior. 
En una segunda reforma a la LOES (la primera se había efectuado en diciembre de 2016), impulsada por un nuevo gobierno en agosto de 2018, se redefine la calidad como

la búsqueda continua, auto-reflexiva del mejoramiento, aseguramiento y construcción colectiva de la cultura de la calidad educativa superior con la participación de todos los estamentos de las instituciones de educación superior y el Sistema de Educación Superior, basada en el equilibrio de la docencia, la investigación e innovación y la vinculación con la sociedad, orientadas por la pertinencia, la inclusión, la democratización del acceso y la equidad, la diversidad, la autonomía responsable, la integralidad, la democracia, la producción de conocimiento, el diálogo de saberes, y valores ciudadanos.

Esta nueva definición establece que la calidad deberá orientarse por los principios que la norma determina actualmente como naturales del sistema: pertinencia, autonomía responsable, integralidad y diálogo de saberes; además, incorpora nuevos principios orientadores de la calidad: inclusión, equidad, diversidad, democracia y valores ciudadanos.

Esta definición se acerca a la de la United Nations Educational, Scientific and Cultural Organization (Unesco), que en su conferencia regional, celebrada en la ciudad de La Habana en 1996, acuerda definir la calidad como "la adecuación del ser y del qué hacer de la educación superior, a su deber ser". El "ser" debe entenderse contenido en la visión, la misión, los principios y los valores de la universidad, y el "quehacer" corresponde a los aspectos operativos y de procedimiento. Estos últimos acercan a las universidades a los ideales propuestos a través de sistemas de aprendizajes, investigación, gestión, autoevaluación y evaluación externa, vinculados al contexto (Gutiérrez et al., 2017).

Extrapolando el concepto de la Unesco al sistema universitario ecuatoriano de 2018, se puede decir que el "ser" está contenido en los principios que constan en el artículo 351 de la Constitución vigente y los declarados en el artículo 93 de la LOES de 2018, mientras que el "quehacer" es sometido a las autoevaluaciones en las IES, y el avance o retroceso hacia esos fines debería ser monitoreado por el CEAACES.

\section{El sistema de evaluación de la Educación Superior en el Ecuador}

Un sistema autónomo de evaluación y acreditación se estableció en el Ecuador con la norma constitucional de 1998 de coordinación y cooperación con el Consejo Nacional de Educación Superior (CONESUP). Es la primera ocasión en la que se declara un sistema para que aborde en su integralidad, de manera 
oficial, a la Educación Superior (Pacheco, 2015: 5). Hasta ese momento, el Estado ecuatoriano había mantenido una relación tradicional con sus universidades. La autonomía universitaria era la principal preocupación y, en algunos casos, se había constituido en una coartada para evitar la rendición social de cuentas. Resultaba inevitable que el Estado iniciara los esfuerzos por articular una respuesta a la expansión de la matrícula, la proliferación de nuevos centros de educación superior y los cambios políticos, económicos y sociales que la propia dinámica de la sociedad ecuatoriana impulsaba.

La Ley de Educación Superior del 2000 señalaba que este sistema estaría dirigido por el Consejo Nacional de Evaluación y Acreditación (CONEA) y que se regiría por su reglamento. En 2002 se expide el Reglamento General y así se viabilizan las acciones del sistema. Habían transcurrido cuatro años desde el mandato de la norma constitucional.

El Sistema Nacional de Evaluación y Acreditación de la Educación Superior se encargaba de la autoevaluación institucional, la evaluación externa y la acreditación. Este proceso se iniciaba con la solicitud institucional al CONEA por parte de la universidad o escuela politécnica que decidiera empezar el proceso. Si de por medio no se encontraba la solicitud, el proceso no arrancaba.

Para 2008, año en que el Mandato 14 de la Asamblea Constituyente ordena al CONEA elaborar el Informe acerca del nivel de desempeño institucional de las IES ecuatorianas, de un total de 62 universidades cinco se encontraban acreditadas, 13 se encontraban en proceso de evaluación externa, 18 habían realizado un ejercicio de autoevaluación y entregado un informe, 11 estaban en la etapa del diseño del proyecto de autoevaluación, nueve no habían iniciado el proceso de autoevaluación y siete no cumplían con el tiempo legal (Villavicencio, 2013: 46).

La lentitud con la que había operado el sistema, la ausencia de cambios relevantes y las denuncias de corrupción en la entrega de títulos académicos eran elementos de preocupación y darían origen a la decisión de la Asamblea Nacional expresada en el Mandato Constituyente No 14.

La integración del CONEA era la siguiente: dos académicos designados por el presidente de la República a partir de ternas elaboradas por la Asamblea universitaria y calificadas por el CONESUP, dos académicos designados por el Congreso Nacional a partir de ternas elaboradas por la Asamblea universitaria, calificadas por el CONESUP; un vocal designado por el Ministro de Educación y Cultura, un vocal designado por las Federaciones Nacionales de los Colegios Profesionales, un vocal designado por el organismo estatal de ciencia y tecnología, y un vocal designado por la Federación de las Cámaras de la Producción. La integración refleja un predominio de académicos provenientes de los organismos objetos de la evaluación y acreditación, así como una marcada injerencia del organismo regulador, CONESUP. 
Después de 10 años, de 1998 a 2008, la nueva norma constitucional pone el acento en los organismos que regirán el sistema de educación superior. Uno de ellos será un organismo técnico de acreditación y aseguramiento de la calidad de instituciones, carreras y programas, y no podrá conformarse por representantes de las instituciones objeto de regulación. La denominación de "sistema" del texto constitucional, en esta ocasión, se utiliza para sustantivar a la Educación Superior; recuérdese que en la Constitución de 1998 se utilizó la denominación de "sistema" para sustantivar los procesos de evaluación y acreditación. La nueva Constitución de 2008 dispone de forma imperativa que, en un plazo de cinco años, sean evaluadas y acreditadas todas las IES, sus carreras, programas y posgrados, y advierte que en caso de no superar la evaluación y acreditación quedarán fuera del sistema de educación superior.

En reemplazo del CONEA, la LOES expedida en 2010 dará origen al Consejo de Evaluación, Acreditación y Aseguramiento de la Calidad de la Educación Superior (CEAACES). Por primera vez aparece el "aseguramiento de la calidad" en la denominación del organismo. El calificado "sistema de evaluación y acreditación” es incorporado a las facultades del nuevo Consejo.

El CEAACES pone en marcha la Disposición Vigésima de la Constitución y realiza las evaluaciones y acreditaciones establecidas para las universidades, escuelas politécnicas y sus extensiones. Asimismo, cumple con el Informe del CONEA y evalúa, dentro de los 18 meses posteriores a la promulgación de la Ley, a las universidades y escuelas politécnicas que fueron ubicadas en categoría E.

La norma constitucional dispone que la Ley establezca los mecanismos de coordinación del sistema de educación superior con la Función Ejecutiva. La LOES, para cumplir con esta disposición, crea la Secretaría Nacional de Educación Superior, Ciencia y Tecnología e Innovación (SENESCYT) para coordinar acciones entre la Función Ejecutiva y las instituciones del sistema de educación superior. Esta secretaría tiene como titular a un funcionario designado por el Ejecutivo. De esta forma, la presencia del Estado, a través de los funcionarios que designa para la regulación, planificación, coordinación, evaluación, acreditación y aseguramiento de la calidad del sistema de educación superior, domina casi la totalidad del espectro del sistema.

Antes de 2008, el Estado había evitado tener una presencia predominante; con la entrada en vigencia de la nueva Constitución y la nueva LOES su rol pasó a ser central en la integración de los organismos que rigen el denominado sistema de educación superior.

La reforma a la LOES de agosto de 2018 incorpora a la SENESCYT como parte del sistema de educación superior. Garantizar el cumplimiento efectivo del principio de calidad corre a cargo del Sistema Interinstitucional de Aseguramiento de la Calidad (SIAC). 
Este nuevo sistema lo integran el CES, el CACES y las IES. A la autoevaluación se le da un carácter permanente y se le convierte en la piedra angular, la que deberá realizarse en referencia a los propósitos de las instituciones. Así, debe entenderse que las misiones y las visiones de las universidades se convertirían en los referentes del citado autoproceso. La acreditación del proceso estará a cargo del CACES, que deberá planificar y coordinar las operaciones. De esta manera, el Estado permanece al frente del sistema aun cuando los procesos de autoevaluación, que son iniciativas de las instituciones universitarias, adquieren centralidad.

Armonizar las dinámicas de los organismos del Estado con las universidades será un proceso por construir. Los procesos internos como las autoevaluaciones, y los externos como las acreditaciones, deberán interrelacionarse, engranarse y funcionar de manera efectiva. Esta interacción está en el horizonte del sistema ecuatoriano.

\section{Aseguramiento de la CALidad}

El CONUEP (Consejo Nacional de Universidades y Escuelas Politécnicas) realizó en 1989 el primer estudio diagnóstico de la universidad ecuatoriana, y uno de los problemas básicos detectados fue la inexistencia de un sistema de educación superior; en su lugar se constataba un conjunto de instituciones independientes unas de otras, con débiles mecanismos de cooperación (Pacheco, 2015: 157). El archipiélago de instituciones universitarias al que alude este estudio tenía en la defensa de la autonomía universitaria un nexo unificador: defender la autonomía resultaba indispensable y no eran pocos aquellos que, al invocarla, le atribuían propiedades taumatúrgicas y la asociaban con la calidad.

Transcurrieron nueve años para que, en la Constitución expedida en 1998, la norma constitucional advirtiera que, para asegurar los objetivos de la calidad, las universidades deberían realizar una rendición de cuentas; para su cumplimiento, se conforma un sistema de evaluación y acreditación. Esta es la primera evidencia normativa de preocupación por la calidad y su aseguramiento.

Dos años después, en el 2000, la Ley de Educación Superior ratifica que el objetivo del sistema de evaluación y acreditación es asegurar la calidad, fomentar procesos permanentes de mejoramiento de la calidad académica y de la gestión, y para ello apela a los procesos de autoevaluación institucional, evaluación externa y acreditación (Valdés y Villegas, 2017: 56).

El objetivo siguiente, establecido en la Ley, era que la sociedad ecuatoriana sea informada del desempeño institucional de los establecimientos de 
educación superior a fin de garantizar la calidad, propiciando su depuración y mejoramiento. La redacción del texto de la norma adolece de falta de claridad; sin embargo, su preocupación por la depuración y el mejoramiento se advierte. El Mandato 14, en 2008, recoge esta intencionalidad y la plasma en sus resoluciones.

Después de las 21 universidades que en 1989 habían sido objeto de evaluación por el CONESUP, se había aprobado la creación de universidades privadas y públicas en un número cercano a las 70, es decir, un aumento de más de 200 \% . A junio de 2006, únicamente la Universidad del Azuay había cumplido con todos los requisitos y se encontraba acreditada.

Un contexto de aplicación de políticas neoliberales en el sistema universitario, de mercantilización de la enseñanza superior e indiferencia del Estado en relación a definiciones y regulaciones, habían introducido caos y descrédito (Lucas, 2015). Reconciliarse con los conceptos de calidad era urgente así como la necesidad de depuración y mejoramiento.

La realidad, el contexto político y el económico imponían su lógica, mientras que la norma quedaba en letra muerta y los organismos se limitaban a contemplar la decadencia.

El Mandato 14 recoge la desilusión del proceso encargado al CONESUP y al CONEA y obliga al CONESUP a elaborar un informe acerca de la situación académica y jurídica (CONESUP, 2009), mientras que demanda al CONEA la entrega de un informe técnico para cumplir con la depuración y el mejoramiento según lo establecido en el artículo 91 de la Ley de Educación Superior de aquella época. En noviembre de 2009 el CONEA entrega su informe, que consta de una inicial clasificación de las universidades ecuatorianas y de una recomendación radical: depurar el sistema universitario ecuatoriano del grupo de universidades que no cumplían con las condiciones básicas de una institución universitaria (La evaluación, 2014). Estas universidades habían sido creadas durante la década de 1990 y los primeros años del siglo XXI.

La LOES de 2010 establece, para estas universidades identificadas en el Mandato 14 tipo E, la prohibición de ofertar nuevos programas académicos y/o cursos de posgrado, y dispone que sean evaluadas en un plazo de 18 meses. Esta evaluación estuvo a cargo del nuevo organismo que la LOES creaba en sustitución del CONEA: el CEAACES. El aseguramiento de la calidad se define como acciones que garantizan la eficiente y eficaz gestión, definición que se extiende a los Consejos y organismos acreditadores.

El aseguramiento de la calidad aparece como un componente del nombre del nuevo organismo; es asumido como un proceso más del sistema. La preocupación en la etapa anterior habían sido la evaluación y la acreditación; ahora, el aseguramiento se constituye en un proceso a implementar, deja de ser 
un objetivo sin concreción. Lo alcanzado es indispensable blindarlo para evitar retroceder, y en paralelo se obliga a alcanzar nuevos niveles de mejoras.

En la etapa de 2010 a 2018 el CEAACES efectúa evaluaciones de carreras, exámenes para habilitación del ejercicio profesional, depura extensiones, participa en intervenciones en universidades, recategoriza y acompaña procesos de planes de mejora, de fortalecimiento institucional y de la calidad. Finalmente, en 2018 nos encontramos con un aseguramiento de la calidad cuyos resultados arrojan una realidad asimétrica que se oculta en la acreditación de 55 universidades de un total de 59, 39 extensiones y 56 carreras evaluadas. Los exámenes de habilitación para el ejercicio profesional se han aplicado en carreras que pudieran comprometer el interés público, poniendo en riesgo esencialmente la vida, la salud y la seguridad de la ciudadanía; entre 2015 y 2018 los exámenes de habilitación para el ejercicio profesional (EHEP) se han aplicado en nueve ocasiones para los estudiantes de las carreras de Medicina, siete veces para la carrera de Odontología y en dos ocasiones para estudiantes de la carrera de Enfermería.

La reforma a la LOES en agosto de 2018 tiene como línea de base unas IES cuya calidad ha sido acreditada desde la asimetría (Espinosa, 2016: 43). Así, en la página web oficial del CEAACES constan 18 universidades en la categoría C, 28 en la categoría B y 8 en la categoría A. Las universidades categorizadas $\mathrm{C}$, que corresponden a 30 \% de las IES, deben acelerar sus procesos de mejoramiento a fin de reducir la brecha actualmente existente; en situación semejante se encuentran las categorizadas B en relación con las A.

De otra parte, la norma no contempló ni contempla un proceso de reaseguramiento para el sistema. Ni el CONEA en su momento ni el CEAACES desde 2010 a 2018 han sido evaluados técnicamente por organismos independientes para asegurar que su tarea efectivamente cumple con estándares aceptables.

\section{COMUnicación DE LA CALIDAD}

La comunicación es una necesidad humana. Las instituciones educativas, integradas por seres humanos, que entregan servicios a comunidades humanas, tienen una ineludible necesidad de comunicarse (Meza, 2017). No es suficiente entregar información acerca de lo que hacen y cómo lo hacen: conocer lo que piensan y sienten acerca de la información que entregan a sus receptores para luego retroalimentarse, decantar y reconstruir el nuevo mensaje para volverlo a acercar al punto donde se logren modificar patrones culturales es un camino que deberían transitar las IES para comunicar sus esfuerzos por asegurar la calidad (Jaya y Guerra, 2017: 208). 
Este camino no ha sido recorrido por el sistema universitario ecuatoriano en el proceso por asegurar la calidad de la educación superior. El papel protagónico que el Estado asumió desde 2008 se tradujo en una política de comunicación vertical, autoritaria, que hizo que los organismos encargados de la calidad renunciaran a políticas y estrategias de comunicación propia y en sustitución promovieron políticas comunicacionales institucionales, fundamentalmente a través de la página web, destinada a posicionar perfiles positivos de los integrantes del organismo.

Así lo expresó el presidente del CEAACES al responder a la petición, por parte de la Asamblea Nacional del Ecuador, de información acerca de las políticas y estrategias de comunicación. Sostuvo que el ordenamiento jurídico vigente no le atribuye al CEAACES esa competencia, pero que en la página web institucional se encuentra información para orientar a quien lo desee. En conclusión: el organismo asegurador de la calidad jamás se planteó y en consecuencia nunca ejecutó una política de comunicación para promover el aseguramiento y buscar un empoderamiento que se constituya en nuevos patrones de conducta en las IES.

En el Plan comunicacional de 2017 se encuentra que el objetivo general de comunicación anual del CEAACES en el Ecuador consiste en "contribuir a través de acciones de comunicación interna y externa con el cumplimiento de la planificación institucional del Consejo de Evaluación, Acreditación y Aseguramiento de la Calidad de la Educación Superior, para posesionar las atribuciones y funciones del Consejo asociadas a gestión de aseguramiento de la calidad". Con la finalidad de constatar su cumplimiento a través de los objetivos específicos, se desarrolló una investigación exploratoria de las páginas web de las IES ecuatorianas.

\section{Metodología}

La revisión de las páginas web fue integral y directa, analizando todos los componentes e hipervínculos de la misma, bajo el enfoque de los seis objetivos específicos propuestos por el CEAACES. El proceso se desarrolló utilizando instrumentos con ítems que indicaban si se cumplía o no el objetivo específico. El instrumento empleado fue el siguiente: 
Nombre de la universidad:

\begin{tabular}{|c|c|c|}
\hline $\mathbf{N}^{\circ}$ & Objetivos específicos & Verificador \\
\hline \multirow{3}{*}{1} & \multirow{3}{*}{$\begin{array}{l}\text { Gestión de la comunicación: generar } \\
\text { una política de comunicación que } \\
\text { defina los lineamientos de la gestión } \\
\text { de la comunicación de la IES. }\end{array}$} & $\begin{array}{l}\text { Existen normativas que regulan la comunicación: } \\
\text { Estatuto, reglamento, instructivo, etc. }\end{array}$ \\
\hline & & $\begin{array}{l}\text { Se promueven actividades de estimulación en el } \\
\text { área de la comunicación: concursos, premios, } \\
\text { sanciones, etc. }\end{array}$ \\
\hline & & $\begin{array}{l}\text { La información publicada refleja las gestiones de } \\
\text { las IES. }\end{array}$ \\
\hline \multirow{3}{*}{2} & \multirow{3}{*}{$\begin{array}{l}\text { Difusión y posicionamiento: promo- } \\
\text { ver espacios de difusión y posicio- } \\
\text { namiento de las IES a través de los } \\
\text { cuales se promueva el conocimiento } \\
\text { y entendimiento de los procesos de- } \\
\text { sarrollados por ellas, para fortalecer } \\
\text { su imagen y reputación institucional, } \\
\text { con información oportuna y clara. }\end{array}$} & $\begin{array}{l}\text { Existe un hipervínculo o viñeta específico de noti- } \\
\text { cias: académicas, sociales, políticas, etc. }\end{array}$ \\
\hline & & $\begin{array}{l}\text { Se realza la imagen y reputación de la IES: resalta } \\
\text { su categoría, acreditaciones, docencia especiali- } \\
\text { zada, etc. }\end{array}$ \\
\hline & & La información publicada es oportuna y clara. \\
\hline \multirow{3}{*}{3} & \multirow{3}{*}{$\begin{array}{l}\text { Imagen de las autoridades: posicio- } \\
\text { nar la imagen del rector, del Órgano } \\
\text { Colegiado Académico Superior - } \\
\text { OCAS, como de otros representantes } \\
\text { oficiales. }\end{array}$} & $\begin{array}{l}\text { Existe un apartado del rector y vicerrector, con } \\
\text { hoja de vida, forma de contacto y otros elementos } \\
\text { informativos. }\end{array}$ \\
\hline & & $\begin{array}{l}\text { Existe un apartado del OCAS, con hoja de vida, } \\
\text { forma de contacto y otros elementos informativos } \\
\text { de todos sus miembros. }\end{array}$ \\
\hline & & $\begin{array}{l}\text { Existe un apartado de otros representantes: } \\
\text { secretaría general, procuraduría, direcciones finan- } \\
\text { cieras, administrativas, talento humano, etc., con } \\
\text { hoja de vida, forma de contacto y otros elementos } \\
\text { informativos. }\end{array}$ \\
\hline \multirow{3}{*}{4} & \multirow{3}{*}{$\begin{array}{l}\text { Vinculación con otras IES: promover } \\
\text { la creación de espacios de vincula- } \\
\text { ción y relación comunicacional con } \\
\text { las IES del sistema, para generar una } \\
\text { red de aliados. }\end{array}$} & $\begin{array}{l}\text { Se evidencian acuerdos interinstitucionales: conve- } \\
\text { nios marcos, específicos, etc., con IES nacionales. }\end{array}$ \\
\hline & & $\begin{array}{l}\text { Se evidencian carreras, programas, investiga- } \\
\text { ciones, etc., desarrolladas en redes ( } 20 \text { más IES } \\
\text { nacionales). }\end{array}$ \\
\hline & & $\begin{array}{l}\text { Se evidencia resultados académicos desarrollados } \\
\text { en redes: libros, artículos, patentes, etc. ( } 2 \text { o más } \\
\text { autores de diferentes IES nacionales). }\end{array}$ \\
\hline \multirow{3}{*}{5} & \multirow{3}{*}{$\begin{array}{l}\text { Gestión institucional con IES } \\
\text { internacionales: promover espacios } \\
\text { de difusión de la gestión institucional } \\
\text { basado en las relaciones que } \\
\text { mantiene la IES con otras a nivel } \\
\text { internacional. }\end{array}$} & $\begin{array}{l}\text { Se evidencian acuerdos interinstitucionales: } \\
\text { convenios marcos, específicos, etc., con IES } \\
\text { internacionales. }\end{array}$ \\
\hline & & $\begin{array}{l}\text { Se evidencian carreras, programas, investigacio- } \\
\text { nes, etc., desarrolladas con IES internacionales. }\end{array}$ \\
\hline & & $\begin{array}{l}\text { Se evidencian resultados académicos: libros, artícu- } \\
\text { los, patentes, etc. desarrollados por } 2 \text { o más autores } \\
\text { de IES internacionales. }\end{array}$ \\
\hline
\end{tabular}




\begin{tabular}{|c|c|c|}
\hline \multirow{3}{*}{6} & \multirow{3}{*}{$\begin{array}{l}\text { Empoderar la misión y visión } \\
\text { institucional: motivar a la comunidad } \\
\text { universitaria para que se empodere } \\
\text { de la misión y visión institucional. }\end{array}$} & Se encuentra publicada la misión y visón de la IES. \\
\hline & & $\begin{array}{l}\text { La información de las carreras vincula a la misión y } \\
\text { visión institucional. }\end{array}$ \\
\hline & & $\begin{array}{l}\text { En general, las actividades publicadas tributan al } \\
\text { cumplimiento de la misión y visión institucional. }\end{array}$ \\
\hline
\end{tabular}

\section{Presentación y ANÁlisis de RESUltados}

Los resultados obtenidos sobre el cumplimiento de los objetivos se presentan a continuación.

\section{Objetivo 1. Gestión de la comunicación}

Generar una política de comunicación que defina los lineamientos de la gestión de la comunicación de la IES.

Sobre este objetivo se tomaron en cuenta tres indicadores:

- La evidencia de normativas que regularan la comunicación de la IES: Estatuto, reglamento, instructivo, etc.

- La evidencia de la promoción de actividades de estimulación en el área de la comunicación: concursos, premios, sanciones, etc.

- La evidencia de que la información publicada refleje las gestiones de las IES.

Resultados

\begin{tabular}{|l|c|}
\hline \multicolumn{1}{|c|}{ 0bjetivo 1 } & Valor relativo (\%) \\
\hline Se cumple con el objetivo & 81 \\
\hline No se cumple el objetivo & 19 \\
\hline Total & 100 \\
\hline
\end{tabular}

Tabla 1. Gestión de la comunicación 


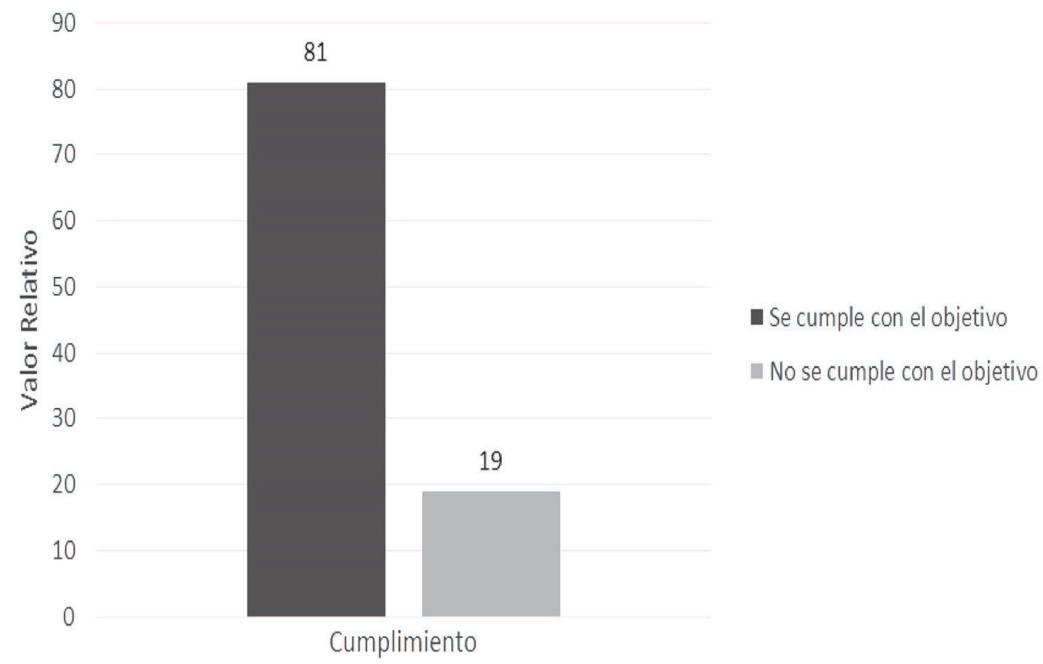

Figura 1. Gestión de la comunicación

Descripción. La existencia de normas evidencia preocupación por regular la comunicación. Se promueven actividades y se estimula la participación de la comunidad universitaria, en especial de los estudiantes. Las actividades de gestión son puestas en conocimiento de quienes acceden a sus páginas web.

Interpretación. Normar para ordenar la comunicación y establecer conductas y acciones al tiempo que se señalan límites y facultades es un paso necesario para institucionalizar políticas comunicacionales. Las actividades a través de las cuales se promueven mensajes con el propósito de que los participantes, directos e indirectos, conozcan y se empoderen de los mensajes, afianzan los objetivos de una estrategia comunicativa. El esfuerzo por acercarse indistintamente a públicos internos y externos para comunicar gestiones tiene los peligros de la imprecisión y de repetir mensajes sin originalidad.

Inferencia. La existencia de normas en $81 \%$ de la universidades del sistema, que regulan la comunicación de las IES así como la promoción y realización de actividades y la comunicación de las gestiones de las IES, por sí solas no garantizan una comunicación de la calidad de educación que se imparte en las universidades. 
Estas actividades, que deberían entenderse como indispensables en una política de comunicación, no las cumplen $19 \%$ de las IES. Este incumplimiento revela desinterés por contribuir a una cultura de la calidad y niega a las audiencias la oportunidad de valorar las ventajas de ser parte o no de una universidad.

\section{Objetivo 2. Difusión y posicionamiento}

Promover espacios de difusión y posicionamiento de las IES a través de los cuales se promueva el conocimiento y entendimiento de los procesos desarrollados por ellas, para fortalecer su imagen y reputación institucional, con información oportuna y clara.

Sobre este objetivo se tomaron en cuenta tres indicadores:

- La evidencia de la existencia de un hipervínculo o viñeta específico de noticias: académicas, sociales, políticas, etc.

- La evidencia del realce de la imagen y reputación de la IES, resaltando su categoría, acreditaciones, docencia especializada, etc.

- La evidencia de que la información publicada es oportuna y clara.

Resultados

\begin{tabular}{|l|c|}
\hline \multicolumn{1}{|c|}{ Objetivo 2 } & Valor relativo (\%) \\
\hline Se cumple con el objetivo & 67 \\
\hline No se cumple el objetivo & 33 \\
\hline Total & 100 \\
\hline
\end{tabular}

Tabla 2. Difusión y posicionamiento

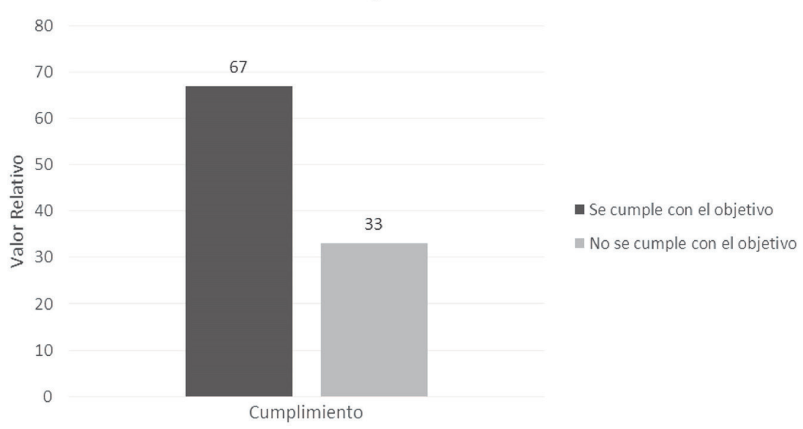

Figura 2. Difusión y posicionamiento 
Descripción. Conocer y entender, por parte de las audiencias internas y externas, aquello que distingue a una universidad de otras, como las actividades académicas y sociales, políticas institucionales vigentes, experticias particulares de la docencia, procesos de acreditación en los que las IES se encuentran implicadas, para fortalecer y promover una imagen institucional que interesa reforzar y/o profundizar.

Interpretación. La imagen, buena o mala, es la primera impresión que se proyecta; en una comunidad universitaria puede resultar determinante al momento de tomar decisiones, como seguir perteneciendo o no a la institución, por ejemplo. La reputación es el resultado de una conducta y acumulado de acciones que en el tiempo han dejado descritas capacidades y/o deficiencias; el prestigio y el buen crédito son un capital que las IES no deberían abandonar ni dilapidar. Constituye también una clara señal de cómo las IES desean relacionarse con quienes son parte de la comunidad universitaria y con los demás integrantes del sistema

La existencia de $33 \%$ de IES a las que la imagen y la reputación institucional le son indiferentes y por lo tanto no se encuentra en sus páginas web evidencia de elementos que transmitan mensajes donde se resalten virtudes y bondades de la universidad da cuenta de un porcentaje importante que se encuentra ajeno y sin entusiasmo en sentirse parte de una cultura que trabaja la calidad de la enseñanza superior.

Inferencia. El $33 \%$ de IES que demuestra indiferencia por la imagen y la reputación institucional constituye un segmento del sistema de educación superior que se muestra impermeable a cultivar políticas de calidad y de aseguramiento. Las políticas de comunicación de los organismos del sistema, CEAACES hoy CACES, deberían dirigirse a estas IES de forma focalizada en el propósito de corregir la asimetría que se observa en el sistema.

\section{Objetivo 3. Imagen de las autoridades}

Posicionar la imagen del rector, del Órgano Colegiado Académico Superior (OCAS), como de otros representantes oficiales.

Sobre este objetivo se tomaron en cuenta tres indicadores: 
- La evidencia de que existe un apartado de información del rector y vicerrector que incluya hoja de vida, forma de contacto y otros elementos informativos.

- La evidencia de que existe un apartado de información del OCAS con hoja de vida, forma de contacto y otros elementos informativos de todos sus miembros.

- La evidencia de que existe un apartado de información de otros representantes de la IES: secretaría general, procuraduría, direcciones financieras, administrativas, talento humano, etc., con hoja de vida, forma de contacto y otros elementos informativos.

\section{Resultados}

\begin{tabular}{|l|c|}
\hline \multicolumn{1}{|c|}{ Objetivo 3 } & Valor relativo (\%) \\
\hline Se cumple con el objetivo & 47 \\
\hline No se cumple el objetivo & 53 \\
\hline Total & 100 \\
\hline
\end{tabular}

Tabla 3. Imagen de las autoridades

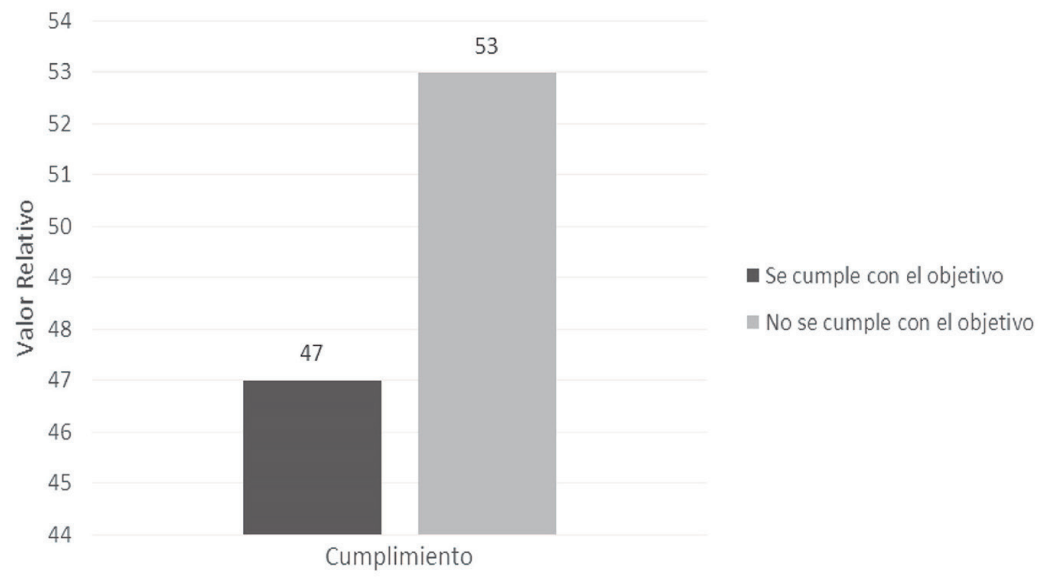

Figura 3. Imagen de las autoridades 
Descripción. Posicionar las imágenes de los representantes oficiales, rectores, vicerrectores e integrantes del OCAS en los lugares de liderazgo que les otorga la designación de la que han sido objeto; es un recurso, un instrumento, una herramienta estratégica que debería permitir que quienes lo ejercen tengan la capacidad de lograr que los demás hagan aquello que en condiciones normales no harían.

Las imágenes de las autoridades académicas y administrativas en las páginas web se presentan como un lugar ideal para una audiencia, interna y externa, que necesita información precisa, confiable y oportuna entregada por parte de los representantes de los organismos oficiales.

Interpretación. A $53 \%$ de las IES del sistema les resulta innecesario comunicar a sus audiencias acerca de quiénes son sus autoridades académicas y administrativas. La ausencia de liderazgos cercanos a quienes forman parte de una institución los deja sin dirección, desorientados.

Es una clara evidencia de que, en algo más de la mitad de las IES ecuatorianas, las autoridades asumen las facultades que les otorgan los nombramientos y designaciones desde la ausencia en el desarrollo institucional. El abandono y alejamiento de las autoridades no contribuyen a la construcción de las identidades de las comunidades universitarias. Por el contrario, se configuran microclimas de inseguridad debido a que se carece de orientación.

Inferencia. La comunicación de los procesos de calidad en la Educación Superior no alcanzará efectividad sin una relación cercana entre las autoridades académicas y administrativas con estudiantes y docentes. Si las necesidades de información específica no son llenadas por las autoridades a quienes se les han otorgado esas facultades, la comunidad universitaria buscará explicaciones acerca del cómo y del porqué en lugares extraoficiales.

\section{Objetivo 4. Vinculación con otras IES}

Promover la creación de espacios de vinculación y relación comunicacional con las IES del sistema para generar una red de aliados.

Sobre este objetivo se tomaron en cuenta tres indicadores:

- La evidencia de acuerdos interinstitucionales: convenios marcos, específicos, etc., con IES nacionales.

- La evidencia de carreras, programas, investigaciones, etc., desarrolladas en redes (dos o más IES nacionales).

- La evidencia de resultados académicos desarrollados en redes: libros, artículos, patentes, etc. (dos o más autores de diferentes IES nacionales). 
Resultados

\begin{tabular}{|l|c|}
\hline \multicolumn{1}{|c|}{ Objetivo 4 } & Valor relativo (\%) \\
\hline Se cumple con el objetivo & 39 \\
\hline No se cumple el objetivo & 61 \\
\hline Total & 100 \\
\hline
\end{tabular}

Tabla 4. Vinculación con otras IES

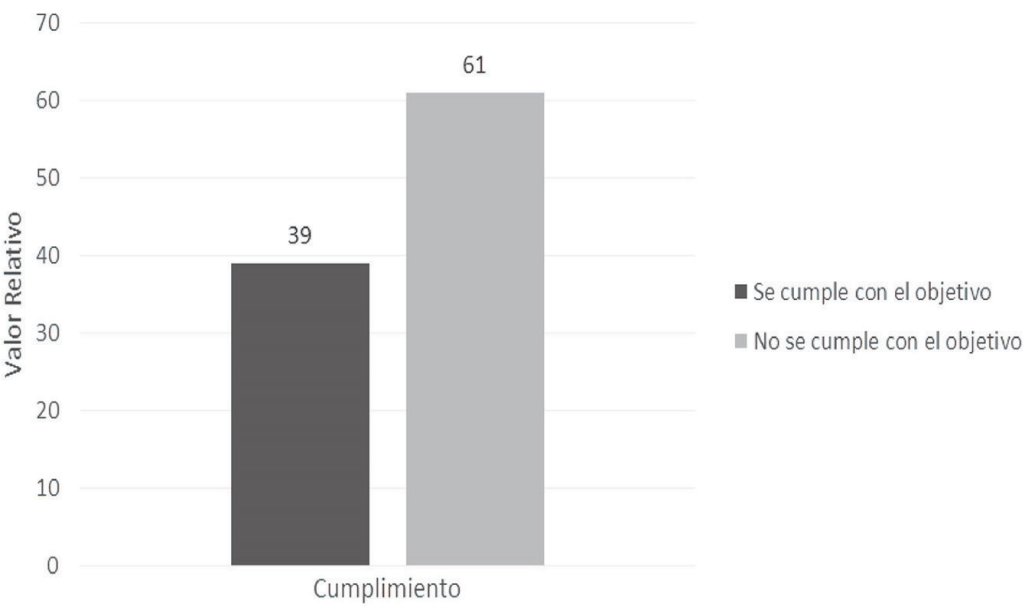

Figura 4. Vinculación con otras IES

Descripción. La cooperación entre IES del sistema de educación ecuatoriano es un asunto que se encuentra inscrito como uno de los criterios de calidad en muchas de las agendas de las políticas y estrategias institucionales. La celebración de convenios, el desarrollo de programas académicos en alianza entre universidades, así como la obtención de resultados expresados en libros, artículos, ensayos es una clara expresión del esfuerzo de las IES por superar la endogamia académica. Desarrollar intercambios de información y metodologías conformando redes de trabajo es una forma de evitar repetirse en procedimientos e iniciar caminos nuevos hacia el mejoramiento de la docencia y la investigación.

Interpretación. El incumpliendo de este objetivo por parte de $61 \%$ de las IES del sistema constituye una renuncia al fortalecimiento y desarrollo institucional así como un elemento de debilidad del sistema universitario ecuatoriano. 
La falta de comprensión de las ventajas que ofrecen los procesos de alianzas, desarrollo de redes y colaboración entre las IES impide la complementariedad entre ellas.

La asimetría existente en el sistema se consolida puesto que las brechas entre universidades categorizadas, fruto de las evaluaciones últimas, se profundizan. Esta priorización mayoritaria de las IES por encerrarse en sí mismas las conduce a idolatrar localismos, evitar la interacción y perder las posibilidades que implica abrir la cultura institucional a la colaboración y a la tolerancia.

Inferencia. Aquellas IES del sistema universitario ecuatoriano que no promueven espacios de cooperación no incorporan uno de los elementos sustanciales de la mejora de la calidad y de la pertinencia que les permitiría promover la cualificación de la docencia, mejorar los procesos enseñanza-aprendizaje, la oferta académica y alcanzar estándares de gestión competitivos. Desaprovechar las oportunidades que ofrece abrir la cultura institucional a las realidades institucionales de otras IES del país lleva al ensimismamiento, cuyas consecuencias serán, entre otras, el agotamiento de metodologías y la incomprensión de los fenómenos y tendencias que se consolidan en IES que están trabajando para proyectarse hacia el exterior.

\section{Objetivo 5. Gestión institucional con IES internacionales}

Promover espacios de difusión de la gestión institucional con base en las relaciones que mantiene la IES con otras a nivel internacional.

Sobre este objetivo se tomaron en cuenta tres indicadores:

- La evidencia de acuerdos interinstitucionales: convenios marcos, específicos, etc., con IES internacionales.

- La evidencia de carreras, programas, investigaciones, etc., desarrolladas con IES internacionales.

- La evidencia de resultados académicos: libros, artículos, patentes, etc. desarrollados por dos o más autores de IES internacionales. 
Resultados

\begin{tabular}{|l|c|}
\hline \multicolumn{1}{|c|}{ Objetivo 5 } & Valor relativo (\%) \\
\hline Se cumple con el objetivo & 39 \\
\hline No se cumple el objetivo & 61 \\
\hline Total & 100 \\
\hline
\end{tabular}

Tabla 5. Gestión institucional con IES internacionales

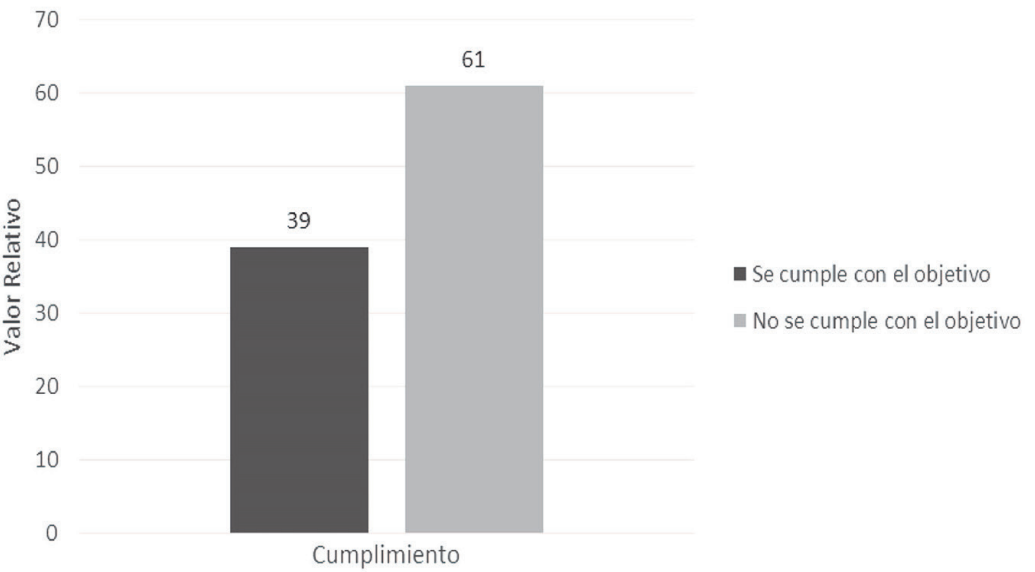

Figura 5. Gestión institucional con IES internacionales

Descripción. La internacionalización de las universidades es un proceso multidimensional que en las políticas de educación superior de Iberoamérica y del mundo ha ido ganando espacio de manera progresiva, al punto que hoy la mayoría de los modelos de evaluación internacional los contemplan como criterios de calidad (Lemaitre y Zenteno, 2012). Este proceso se expresa en acuerdos de diferentes índoles que permiten el desarrollo de programas académicos y de investigación. El intercambio entre estudiantes y docentes, inscripción conjunta de patentes, publicación en conjunto de libros y artículos son expresiones tangibles del proceso.

Interpretación. La coincidencia de que $61 \%$ de universidades ecuatorianas que no cumplen con el objetivo de gestionar sus instituciones hacia el establecimiento de alianzas con IES de otros países y continentes es una consecuencia directa de que este mismo segmento se muestra reacio a la cooperación entre IES ecuatorianas. 
La internacionalización es al mismo tiempo objetivo, que consta en las misiones y visiones institucionales, y proceso de innumerables aristas. Es una de las tantas manifestaciones de la denominada globalización. Las universidades que la asumen lo hacen buscando no sólo captar estudiantes e ingresos sino también como un instrumento que induce cambios en la gestión, organización y producción de conocimientos. Las IES que transitan por este camino están obligadas a introducir mejoras en la calidad de la oferta académica, adecuando su normatividad, cualificando la composición y la formación docente y diversificando contenidos y métodos.

Inferencia. Este $61 \%$ de IES ecuatorianas que no efectúan gestiones hacia la internacionalización de sus instituciones permanecerán ajenas a los procesos de mundialización, a sus luces y a sus sombras. Renuncian de manera voluntaria a acreditar internacionalmente sus programas de estudios y en consecuencia mantendrán su oferta académica en su entorno natural.

\section{Objetivo 6. Empoderar la misión y visión institucional}

Motivar a la comunidad universitaria para que se empodere de la misión y visión institucional.

Sobre este objetivo se tomaron en cuenta tres indicadores:

- La evidencia de que se encuentra publicada la misión y visión de la IES.

- La evidencia de que la información de las carreras vincula a la misión y visión institucional.

- La evidencia de que en general, las actividades publicadas tributan al cumplimiento de la misión y visión institucional.

Resultados

\begin{tabular}{|l|c|}
\hline \multicolumn{1}{|c|}{ 0bjetivo 6 } & Valor relativo (\%) \\
\hline Se cumple con el objetivo & 76 \\
\hline No se cumple el objetivo & 24 \\
\hline Total & 100 \\
\hline
\end{tabular}

Tabla 6. Empoderar la misión y visión institucional 


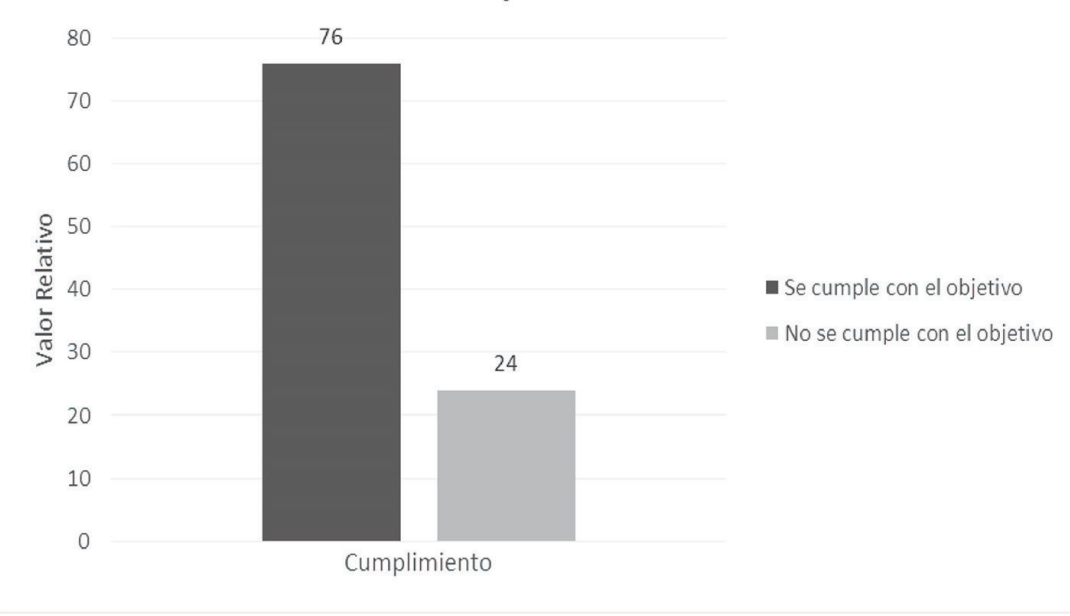

Figura 6. Empoderar la misión y visión institucional

Descripción. Las comunidades universitarias deben conocer los ideales y el futuro anhelado de la institución, así como saber cómo espera hacerlo, el porqué y para quiénes lo va hacer. Es la búsqueda de hacerlos protagonistas de la vida y de las actividades de la universidad. Las visiones y misiones de programas y carreras deben alinearse para contribuir a alcanzar las visiones y misiones institucionales.

Interpretación. Las evidencias de que $76 \%$ de las IES cumplen con difundir información acerca de las misiones y visiones no son halagadoras, puesto que se trata de elementos indispensables para los procesos de institucionalización. La existencia de $24 \%$ que no difunden misiones o visiones se interpreta como ausencia de elementos inspiradores de unidad, de dirección y de propósitos institucionales.

Inferencia. El $24 \%$ de las IES ecuatorianas que no comunican sus visiones y misiones sufrirán las consecuencias inevitables de la falta de planificación: incumplimiento de metas, inadecuada asignación de recursos, pérdida de efectividad, ambiente de incertidumbre por carecer de rumbo, incapacidad de adaptación a los cambios y falta de creatividad e innovación.

Las IES que no sienten la necesidad de transformarse de forma integral y sostenida renuncian a planificar y en su lugar improvisan afectando así la calidad de la educación que imparten. 


\section{Consideraciones finAles}

La investigación exploratoria de las páginas web de las IES ha permitido determinar lo siguiente respecto de las atribuciones y funciones del CEAACES asociadas a la gestión del aseguramiento de la calidad que el Plan comunicacional de 2017 buscó posicionar:

La gestión de la comunicación está normada en 81 \% de las IES. Este es el objetivo específico de mayor cumplimiento. Le sigue el objetivo del empoderamiento de la misión y visión institucional de las IES, con $76 \%$. Con $67 \%$ de cumplimiento se encuentra la comunicación del posicionamiento de las IES del sistema. Luego siguen los objetivos que son cumplidos por menos de la mitad de las IES: imagen de las autoridades con $47 \%$, vinculación con las otras IES del sistema con $39 \%$ y gestión institucional con IES internacionales, con $39 \%$.

Se constata que predomina la preocupación por elaborar normas, reglamentos y/o estatutos. La existencia de éstos no es garantía de que tengan una aplicación cabal; es, sin embargo, una señal de tener consciencia de la necesidad de comunicar los elementos que conforman la calidad institucional.

El empoderamiento de $76 \%$ de la misión y visión institucional es señal de un conocimiento mayoritario de hacia dónde se quiere ir, de lo que quieren hacer, del porqué lo quieren hacer y para quiénes quieren hacerlo. Sin embargo, la evidencia declarativa no es suficiente para afirmar que en la realidad ese empoderamiento se concreta en hechos.

$\mathrm{El}$ incumplimiento por parte de $61 \%$ de instituciones que se presenta en la vinculación entre IES nacionales y la internacionalización de las mismas es evidencia de una mayoritaria vocación por el contexto inmediato y provincial.

La docencia y no la investigación como eje hegemónico de las IES favorece la incomunicación y la ausencia de relación entre la mayoría de las universidades del mismo país. Este aislamiento entre IES nacionales impide que se materialicen la actualización curricular, la oferta tecnológica, la ampliación de la oferta docente, las investigaciones conjuntas y las reingenierías de la gestión y organización institucional, en un ambiente de colaboración. En el caso de las universidades públicas, en el contexto de crisis económica, la racionalización presupuestaria y procesos complementarios de gestión, estarían entre los beneficios que con urgencia se demandan y que podrían alcanzarse.

Además, la brecha de la calidad entre las IES ecuatorianas que fueron categorizadas A, B, C y D antes de agosto de 2018 tendría un escenario que favorecería su acortamiento si la vinculación y los nexos institucionales se establecieran en un escenario de asociación complementaria.

El $61 \%$ de incumplimiento que se presenta con la promoción de espacios de difusión de la gestión institucional con base en las relaciones que 
mantienen las IES con otras a nivel internacional revela que este aspecto aún no forma parte de la cultura y de las estrategias institucionales. La mayoría de las IES se sienten alejadas de este objetivo. No se advierte un mayoritario compromiso institucional, requisito previo para cualquier política de internacionalización, que eluda la resistencia al cambio y a las oportunidades que ofrece en la comprensión de las tendencias globales, la multiculturalidad y el ejercicio de la tolerancia y de la solidaridad.

Este incumplimiento abre la puerta a la presencia de oferta académica internacional, en especial la oferta en la modalidad a distancia y en línea, que está a la espera de oportunidades para hacerlo. Cabe recordar que la normatividad en lo concerniente a la oferta académica trasnacional únicamente contempla las alianzas que voluntariamente puedan establecerse con IES nacionales y en todos los otros aspectos es inexistente.

Las consecuencias que se derivan en esta aproximación exploratoria son un sistema con organismos estatales que no logran armonizar sus planes con los demás integrantes del sistema y las IES ecuatorianas con una mirada mayoritaria clavada en el relativismo de lo local sin mayor interés por romper ese techo, mientras que una minoría de IES realizan esfuerzos por adecuar la oferta académica de cara a las exigencias de las acreditaciones internacionales, buscando ponerse a tono con las corrientes globales de la Educación Superior de mejora de la calidad, y así ampliar las oportunidades del fortalecimiento y evolución institucional.

Agradecimientos

Se deja expreso agradecimiento a la Universidad Estatal de Guayaquil y a la Universidad Estatal Península de Santa Elena por sus aportes administrativos y económicos para el desarrollo de la presente investigación, por medio de sus Observatorios de Políticas Públicas y Sociales.

\section{REFERENCIAS}

Cadena, Francisco. 2014. La evaluación de la calidad de la Universidad ecuatoriana. La experiencia del Mandato 14. Ecuador: Consejo de Evaluación, Acreditación y Aseguramiento de la Calidad de la Educación Superior.

Cielo, Cristina, Pablo Ospina y Cristina Vega. 2016. Reforma y renacimiento: conversaciones docentes sobre la reforma universitaria en Ecuador. Ecuador: Universidad Andina Simón Bolívar. 
CONESUP (Consejo Nacional de Educación Superior). 2009. Autonomía Universitaria. Legislación comparada de nueve países de América Latina y España. Ecuador: Consejo Nacional de Educación Superior.

Espinosa, Alfonso. 2016. Reforma y Renacimiento: Conversaciones docentes sobre la reforma universitaria en Ecuador. Ecuador: Corporación Editora Nacional.

Gutiérrez, Rodrigo, Paola Sainz, Atenas Contreras, María Lugo, Teresa Preciado y José Ornelas. 2017. Universidad sustentable. México: Instituto Tecnológico y de Estudios Superiores de Occidente. https://rei.iteso.mx/bitstream/handle/ 11117/5216/Universidad\%20Sustentable.pdf? sequence $=3$

Jaya, Aida y Rosa Guerra. 2017. "El liderazgo y la participación como factores clave para la gestión de la calidad. Caso de la Universidad Estatal de Bolívar". Cofin Habana 11 (2): 206-225. http://scielo.sld.cu/pdf/cofin/v11n2/cofin15217.pdf

La evaluación de la calidad de la Universidad ecuatoriana. La experiencia del Mandato 14. 2014. Ecuador: Consejo de Evaluación, Acreditación y Aseguramiento de la Calidad de la Educación Superior.

Lemaitre, María y María Zenteno. 2012. Aseguramiento de la calidad en Iberoamérica. Educación Superior - Informe 2012. Chile: Centro Interamericano de Desarrollo CINDA - UNIVERSIA.

LOES (Ley Orgánica de Educación Superior). 2010. Ecuador: Registro Oficial, Ley Núm. 16, RO/77.

López, Martha, Luz Cifuentes y Ana Palma. 2018. "La gestión de las políticas públicas en las universidades: una aproximación a su caracterización en el Ecuador". Dominio de las Ciencias 4 (1): 447-464.

Lucas, Kinto. 2015. De los bancos de papel a las universidades de garaje: impactos de las políticas neoliberales en la educación superior en Ecuador. Ecuador: Consejo de Educación Superior.

Martínez, Andrés y Paula Vázquez. 2012. "La importancia de la evaluación en las instituciones educativas conforme a la nueva ley orgánica de educación superior en el Ecuador". Revista Iberoamericana de Evaluación Educativa 5 (2): 174-180. https://repositorio.uam.es/bitstream/handle/10486/661737/RIEE_5_2_13.pdf?sequence=1

Meza, José Luis. 2017. "Relaciones Públicas Internacionales: Un análisis de la estructura y conductas de comunicación para la internacionalización universitaria”. Observatorio 11 (1). obs.obercom.pt/index.php/obs/article/ download/878/pdf

Molina, Susana. 2015. "Evaluación de las bibliotecas universitarias ecuatorianas: análisis del entorno y propuesta de un catálogo de indicadores". Tesis de grado doctoral. Universidad de Barcelona. Facultad de Biblioteconomía y Documentación.

Molitor, Michel. 2009. La Universidad en la tormenta. Ecuador: Editorial Universitaria ABYA-YALA.

Pacheco, Lucas. 2015. La primera evaluación de la Universidad ecuatoriana (19801988). Quito: Consejo de Educación Superior CES.

Toscanini, Mauro, Antonio Aguilar y Roberto García. 2016. "Diagnóstico de las políticas públicas de la educación superior en el Ecuador”. Revista Cubana de Educación Superior 35 (3): 161-178. http://s.sld.cu/pdf/rces/v35n3/rces133 16.pdf

Valdés, Miguel y Tania Villegas. 2017. "Responsabilidad social universitaria: fundamento para la gestión sociocultural”. Revista Cubana Educación Superior 36 (3). http://scielo.sld.cu/pdf/rces/v36n3/rces05317.pdf 
Villarroel, César. 2004. La calidad universitaria: aspectos conceptuales y operativos. Ecuador: CONEA.

Villavicencio, Arturo. 2013. De la universidad funcional a la universidad de la razón. Quito: Universidad Andina Simón Bolívar.

Para citar este texto:

Santa-María, Guillermo, Carina Rey-Martin, Lilian Molina-Benavides y Arturo Clery. 2019. "La calidad de la comunicación de las Instituciones de Educación Superior del Ecuador". Investigación Bibliotecológica: archivonomía, bibliotecología e información 33 (81): 13-39.

http://dx.doi.org/10.22201/iibi.24488321xe.2019.81.58044 